\title{
Effects of Fenitrothion on some histo-architecture of freshwater fish Channa punctatus
}

\author{
M.A. Akhter ${ }^{1}$, A.K. Saha ${ }^{2}$ \\ ${ }^{I}$ (Department of zoology, kurigram Govt. Woman's College, Bangladesh) \\ ${ }^{2}$ (Department of zoology, University of Rajshahi, Bangladesh)
}

\begin{abstract}
The presence of insecticide in the environment, due to extensive use in agriculture is of potential toxicological concern for fish. Histotoxicological studies have been widely used as biomarkes in the evaluation of the health of fish exposed to the pesticides studies. In the present study the hazardous effect of the organophosphate insecticide, Fenitrothion on the histology of the fresh water fish (Channa punctatus) after exposure for 21 days was investigated. Fish used in the experiment was nearly similar weight and length. The treated groups were compared with the control group for the histological changes in the selected tissue (kidney, liver and heart) and marked changes were observed.
\end{abstract}

Keywords - Fenitrothion, Histology, Liver, Kidney, Heart

\section{Introduction}

Ecotoxicology is the incorporation of ecology and toxicology. The appraisal of the ecotoxicological risks caused by pesticides to ecosystems is based on toxicity data and the effects of pesticide preparations on non-target organisms (1). Pesticides have been used in agriculture to enhance the production of food by eradicating unwanted insects and controlling disease vectors (2). But the increasing chemization in all areas of man's activities has off-putting impact also besides its benefits. Though they have contributed considerably to agricultural outcomes, their adverse effects on non-target organisms are significant (3).

Bangladesh is an over populated country with its high growth rate. The country mainly depends on agricultural products to feed its people. So a large amount of agro-chemicals and insecticides are used to enhance the agricultural production from a limited land to meet the demand of food grains for country's ever increasing population. The aquatic ecosystem is contaminated by indiscriminate and wide spread of pesticides and other metallic pollutants in controlling the agriculture pests. The freshwater ecosystems are adversely affected by the pesticides (4). The contamination of surface waters by pesticides used in agriculture is a problem of worldwide importance (5).

Sumithion has been widely used for more than 30 years for various agricultural applications around the world. But application of sumithion indirectly affected greatly the aquatic environment and specially the fresh water fish. Fenitrothion is an active compound of Sumithion (6). Fenitrothion is moderately toxic by ingestion, inhalation and dermal absorption. Bioaccumulation cause serious risk to life. Such toxic substances enter to human through food chain, as fishes constitute an important part of animal protein in rural and urban areas. Fish, among the group of non-target aquatic organisms, represent the largest and most diverse group of vertebrates. A number of characteristics make them excellent experimental models for toxicological research, especially for the contaminants which are likely to exert their impact on aquatic systems $(7,8,9 \& 10)$.

Histopathological changes have been widely used as bio marks in the evaluation of the health of fish exposed to contaminant. Accumulation of the toxic chemical pollution is known to adversely affect the liver, kidney, muscles and other tissues of fish. The present study aimed to investigate the impact of the Fenitrothion on the histological structures of the liver, kidney and heart of snakehead, Channa punctatus is a fresh water popular fish species in Bangladesh called Taki is an important and abundant in the natural water bodies.

\section{Materials And Methods}

Living and healthy specimens of Channa punctatus were collected from local fresh water sources. The fishes were stored in a plastic aquarium containing $50 \mathrm{~L}$ de-chlorinated tap water for 10 days for acclimation under laboratory conditions. Water was changed after every $24 \mathrm{hrs}$. Commercial fish food was supplied to fish during acclimation period. Temperature: $28 \pm 2^{\circ} \mathrm{C}$, pH: $7.0 \pm 0.2$ were maintained. Adult fish weighing $(21 \pm 1.9$ g) and length $(10-12 \mathrm{~cm})$ were selected for experiments. Acclimated fishes were treated with Fenitrothion EC $50 \%$.

In the present study five treatments were used to investigate the effects of Fenitrothin. The fishes were treated with different concentration of Fenitrothion like 10, 20, 30, 40 and $50 \mu 1 / 1$ for 21 days to observe the histological changes. Control fishes were maintained pesticide free de-chlorinated tap water in separate 
container during this experiment. Mortality was recorded every $12 \mathrm{hrs}$ during these periods. Both experimental and control groups of fishes received the same diet through the experiment. Each container has ten fishes.

After 21 days survived fishes of both treated as well as control groups were killed by decapitation. After decapitation, the blood was allowed to drain and the fishes were dissected open to take out liver, heart and kidney. Tissues were taken into saline solution for times to remove any blood and debris attached on the external surface and fixed in Bouin's fluid for 18 hours, after fixation dehydrated, embedded in paraffin wax and sectioned at 4-6 $\mu \mathrm{m}$ then stained with haematoxylin and eosin and examined microscopically (11).

\subsection{Toxicity assay}

\section{Results}

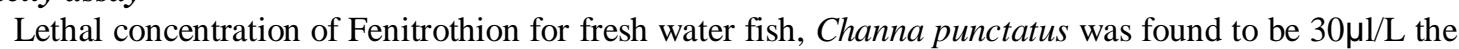
upper and lower $90 \%$ confidence limits were found to be $40 \mu \mathrm{l} / \mathrm{L}$ and $20 \mu \mathrm{l} / \mathrm{L}$ respectively (Table 1 ).

TABLE 1. Mortality rate of fresh water fish Channa punctatus at different concentration of Fenitrothion at 21days exposure of Fenitrothion

\begin{tabular}{lllll}
\hline Sl. No. & $\begin{array}{l}\text { Concentration of } \\
\text { Fenitrothin } \mu \mathrm{L} / \mathrm{L}\end{array}$ & $\begin{array}{l}\text { No. of fishes } \\
\text { exposed }\end{array}$ & $\begin{array}{l}\text { No. of fishes } \\
\text { dies }\end{array}$ & $\begin{array}{l}\text { Percentage of } \\
\text { Mortality }(\%)\end{array}$ \\
\hline 1 & 10 & 10 & 1 & $10 \%$ \\
2 & 20 & 10 & 3 & $30 \%$ \\
3 & 30 & 10 & 5 & $50 \%$ \\
4 & 40 & 10 & 7 & $70 \%$ \\
5 & 20 & 10 & 8 & $80 \%$ \\
\hline
\end{tabular}

\subsection{Liver of control groups}

Liver is bi-lobed organ, having a homogenous mass of polygonal hepatic cells or hepatocytes with centrally located nuclei and a granular cytoplasm. Hepatocytes arranged a central vein into which blood flows from sinusoids (Fig. 1 a).

\subsection{Liver of treatment groups}

The most common lesions in the liver of studied fishes were parenchymal vacuolation, vacuolar degeneration in the hepatocytes, focal areas of necrosis. Dialation and thrombosis formation in central vein, dialation and congestion in blood sinusoids, blood vessels inside the hepatic tissue were observed Moreover hydropic degenerations, fatty infiltration, necrosis, fibrosis were seen in the liver tissue of Channa punctatus treated with Fenitrothion (Fig.1 b, c, d, e, f, g \& h).

\subsection{Kidney of control groups}

The functional unit of kidney of Channa punctatus is the nephrone. Each of which consists of a renal corpuscle and a renal tubule. The renal corpuscle of nephron consists of glomerulus and Bowman's capsule. Other regions of the renal tubule are proximal, distal and collecting tubules. The normal histological structure of kidney shows the control group (Fig. 2 a).

\subsection{Kidney of treatment groups}

The histopathological alternation in kidney of Channa punctatus, exhibiting severe degenerative and necrotic changes in renal tubules with focal areas of necrosis and haemorrhage. Vacuolar degeneration (Cloudy Swelling) in the epithelium of renal tubules and dialation in the capillary tubes of renal tubules were observed. Also oedema in Bowman's capsule with atrophy in glomeruli and severe haemorrage were observed (Fig. 2 b, c, d, e, f \& g).

\subsection{Heart of control groups}

Heart of control shows normal arrangement of longitudinal muscle and its exhibit epicardium, myocardium, endocardium in normal shape (Fig. 3 a1 \& a2). Figure showing the normal blood vessel in longitudinal muscle.

\subsection{Heart of treatment group}

Low concentration no significant changes were found. At high concentration heart tissue exhibited remarkable changes in the pericardium as well as myocardium. The heart with Fenitrothion showed fragmentation of muscle fibers with splitting of muscles, infiltration and degeneration. It also was showing pyknosis, necrosis, brown atrophy and oedema in muscle bundle (Fig. 3 b, c, d, e \& f). 

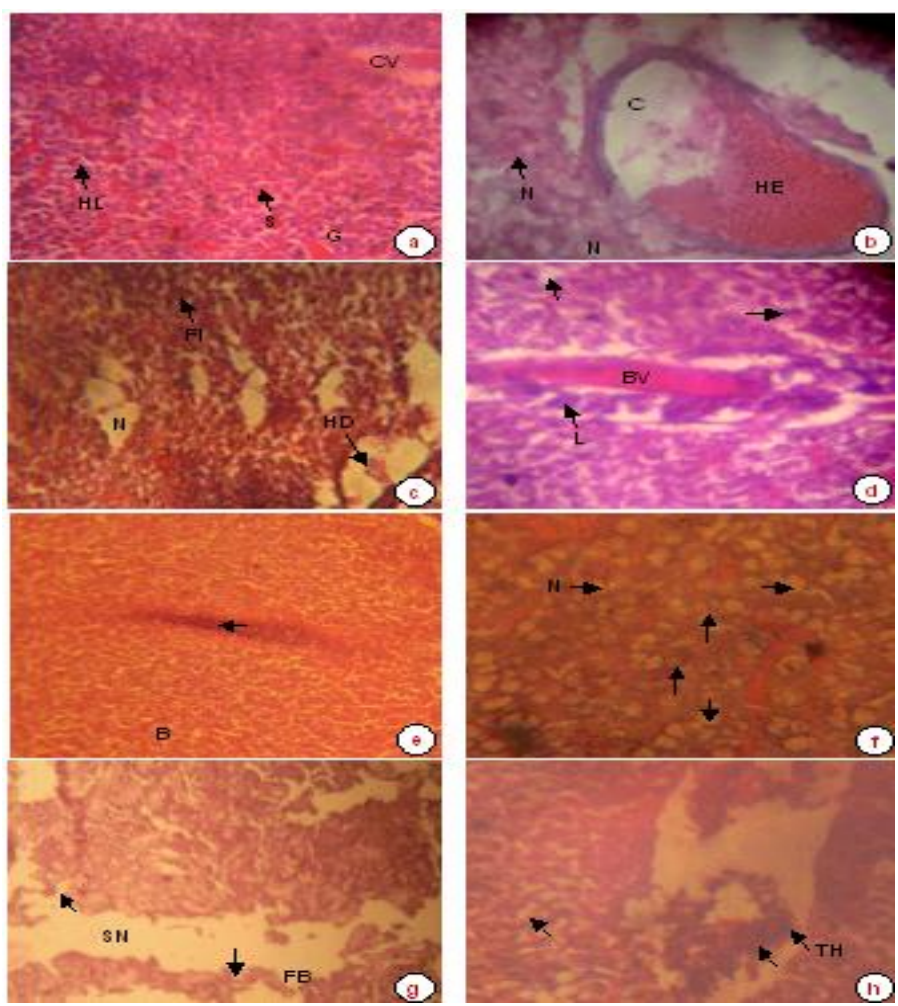

FIGURE 1. Histological study of liver of Channa punctatus

(a) Section of control liver exposed laminae of hepatocytes $(\mathrm{H})$ arranged around central vain $(\mathrm{CV})$ into which blood flows from sinusoids (S); (b) Severe haemorrhage (HE) in central vain, vaculation (V) and focal coagulative necerosis (CN) in the liver treated with Fenitrothion; (c) Dialation and hydropic degeneration (HD) and fatty infiltration (FI); (d) Blood vessels inside the hepatic tissue (BV) aggregations of inflamatory cells between the hepatocytes in treated liver; (e) Dialatioon and congestion in blood sinusolds; (f) Section of liver exposed parenchymal vaculation (arrow), necrosis $(\mathrm{N})$; (g) Section exposed severe necrosis $(\mathrm{SN})$, fibrosis (FB); (h) Dialation and thrombosis formation in centatl vain $(\mathrm{TH})$.
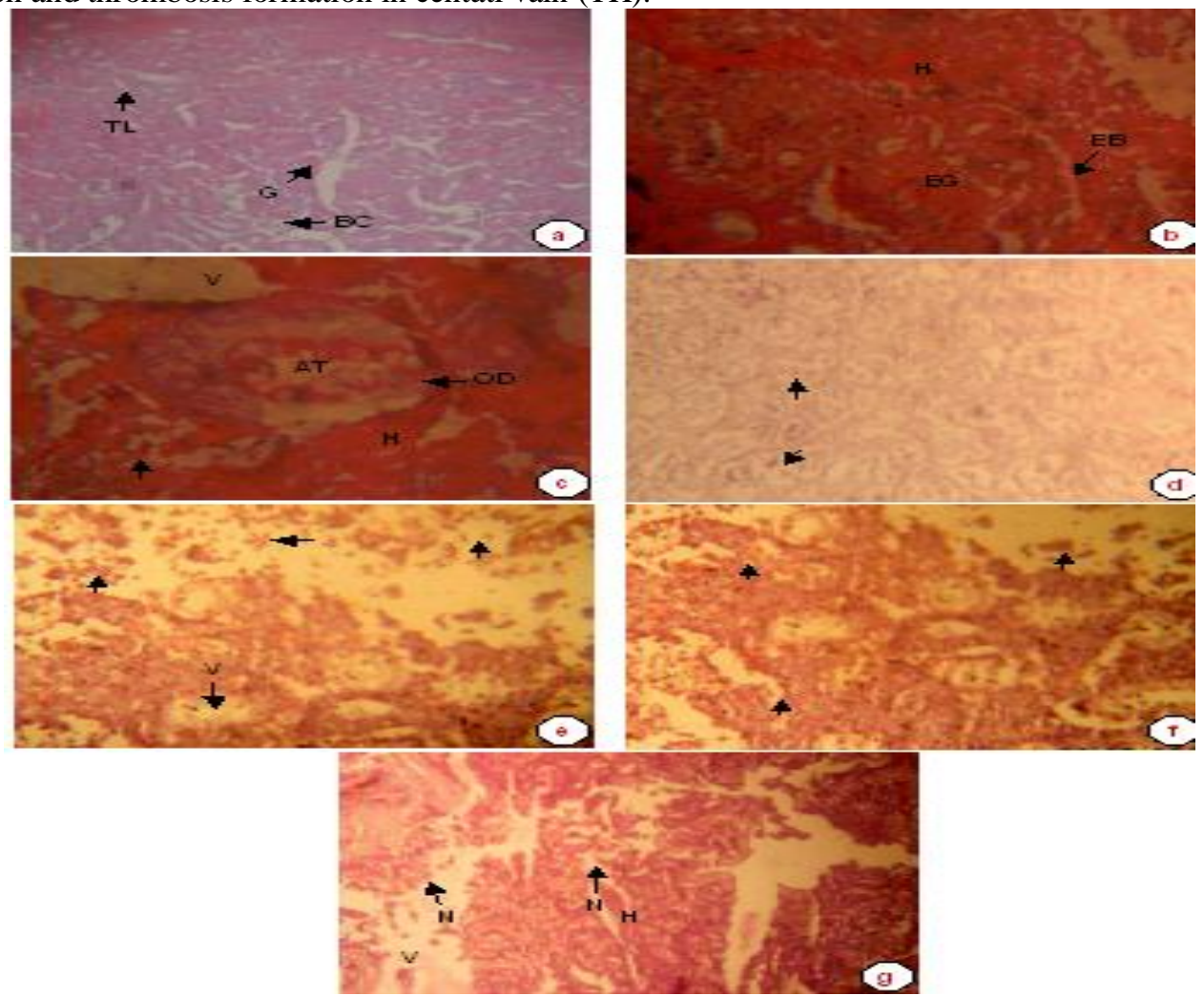

FIGURE 2. Histological study of kidney of Channa punctatus 
(a) Kidney of control fish (Channa punctatus) showing glomerulu (G), Bowmais capsul (BC), tubular lumen (TL); (b) Section of kidney showed haemorrhege (H), enlargement of Bowman's capsul, (EBC) and glomerulus (EG) in treated kidney; (c) Vacuolation arround the capsu (V), severe hemorrhage (H), oedema in Bowman's (OD) capsuls with atrophy in glomeruli (AT); (d) Vacular degeneration with aggragatory inflammatory cells (arrow); (e) Severe degenerative and necrotic changes in the renal tubules with focal areas of necrosis (arrow), vaculation in Bowman's capsul (V); (f) Section of treated kidney exposed severe degeneration and necrosis changes in the renal tubules with focal area of necrosis (arrow); (g) Vacular degeneration in renal tubules and swelling necrosis in the epithelium of the renal tubules of the kidney (arrow).

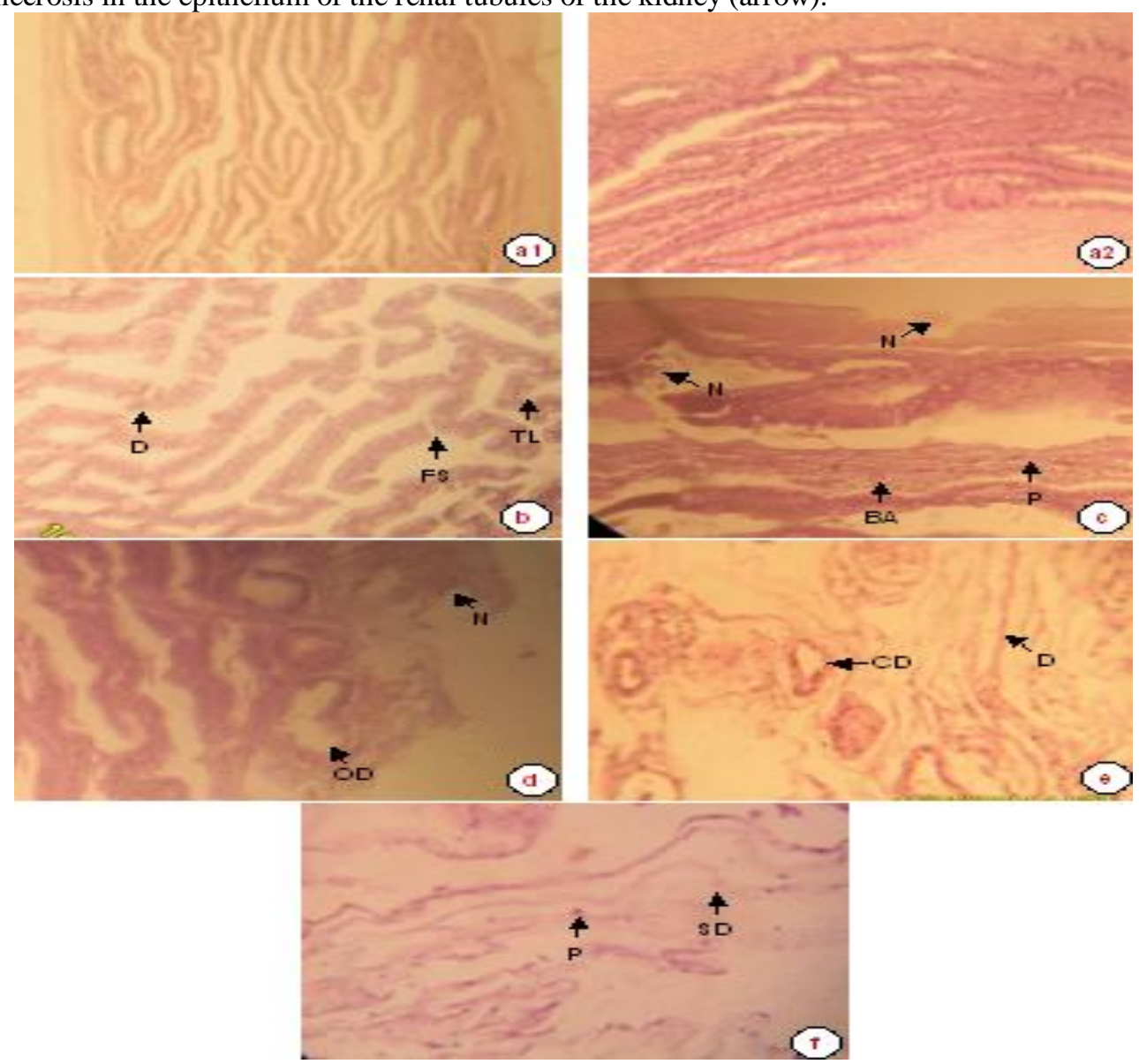

FIGURE 3. Histological study of heart of Channa punctatus

(a1 \& a2) Heart of control group shown normal arrangement of longitudinal muscles and other cardiac muscular layer; (b) Section of treated heart showing fragmentation of muscle fibres with splitting of muscles (FS), Infiltration (IL) and degeneration (D); (c) Section of heart showing Pyknosis (P), necrosis in muscular layer (N), brown atrophy (BA); (d) Accumulation of oedema fluid in atrium muscle bundle (arrow), necrosis degeneration $(\mathrm{N})$; (e) Degeneration of muscle (D), oedema (OD); (f) Severe degeneration (SD) and pyknosis (P).

\section{Discation}

Histopathological alterations can be used as indicators for the effects of various anthropogenic pollutants on organisms and are a reflection of the overall health of the entire population in the ecosystem. These histopathological biomarkers are closely related to other biomarkers of stress since many pollutants have to undergo metabolic activation in order to be able to provoke cellular change in the affected organism (12).

The liver, as the major organ of metabolism, comes into close contact with xenobiotics absorbed from the environment and liver lesions are often associated with aquatic pollution. The organ most associated with the detoxification and biotransformation process is the liver and due its function, position and blood supply, it is also one of the organs most affected by contaminants in the water (13).

In the present study, histopathological changes in the liver by Fenitrothion, parenchymal vacuolation, necrosis, degeneration of hepatic mass were observed. Akter, et al. reported similar result of vaculation in the hepatic cell and necrosis in liver (14). Pugzhuenda found large vacolation, necrosis, proliferation of hepatic cells and cirrhosis due to exposed malathion (15). Parikh, et al. observed marked swelling, vascular degeneration of hepatocyte (16). This change attributed to direct toxic effects of pollutants on hepatocytes. Since the liver is the site of detoxification of all types of toxics and chemicals (17). Rodrigues, et al. Camargo, et al. and Mohamed 
was also reported parallel observations with pesticides investigations on fishes $(18,13 \& 19)$. The present results are in agreement with those observed by many authors who have studied the effects of different pollutants on fish liver $(20,21 \& 22)$ also observed degeneration of the hepatocytes and focal necrosis in the liver of Clarias gariepinus exposed to lead. Exposure of Oncorhynchus mykiss to copper sulphate was found to induce degeneration of hepatocytes, sinusoidal dilation and congestion in the blood vessels of the liver (23).Many histopathological changes in the liver of catfish Clarias gariepinus was also observed by Sak, et al. (24). Cytoplasmic vaculation, of the hepatic cells, inflammatory leucocytic infiltrations, congestion of blood vessel, necrosis and fatty infiltrations was observer. This result is similar to present study. Similarly, Teh, et al. found the exposing 7-day old larvae of the fish Sarcomento splittail to sub-lethal concentration of esfenvalerate for one week induced vacuolar degeneration and cell necrosis in the liver (25).

The kidney is a vital organ of body and proper kidney function is to maintain the homeostasis. It is not only involved in removal wastes from blood but it is also responsible for selective re-absorption, which helps in maintaining volume and $\mathrm{pH}$ of blood and body fluids and erythropoieses (26). The kidney is one of the first organs to be affected by contaminants in the water (27) .

In the present study, kidney of the fish showed vacuolar degeneration (cloudy swelling) in tubules cells. In more severe cases, the degenerative process leads to tissue necrosis (28). The present results are in agreement with those observed in C. carpio exposed to sewage (29), P. lineatus exposed trichlorfon (30) and $L$. calcarifer exposed to cadmium (27). Velmurugan, et al. reported, histological changes in kidney of $C$. mrigala, exibiting necrosis of tubular epithelium, hypertrophied epithelial cells of renal tubules, expansion of space inside the Bowman's capsules exposed to fenvalerate (31). Similar observation made by Parikh et al exposed dimethoate in Oreocromis mossambicus (16). Camargo and Martinez found cloudy swelling degeneration in the epithelium of renal tubules in the kidney of $P$. lineatus caged in Camber stream, Brazil, polluted by industrial, domestic and agricultural wastes also agreement with present observation (13). The present results are in agreement with those observed by Iqbal, et al. reported degeneration of glomeruli, increase in Bowman's space, intra-tubular hematopiotic tissue were observed in fish kidney after nitrate exposure (26).

The common alterations found in the study were severe degenerative and necrotic changes in the renal tubules with focal areas of necrosis, hemorrhage between renal tubules and oedema in Bowman's capsules with atrophy in the glomeruli which are similar to Mohamed findings (19).

During present investigation heart showed no change at low concentration. Heard tissue exhibited remarkable changes in the pericardium as well as myocardium. The pericardial sac moderately thickened and infiltrated extensively, atrium muscle bundles were separated by an accumulation of oedema. The observations are similar to the findings on Labeo rohita exposed to hexachlorocyclohexane (32). More or less similar histological changes were observed by Riaz et al. in quail chicks (33).

\section{Conclusions}

The present study proves the toxic potential of the Fenitrothion and shows several alterations in kidney, liver and heart. Furthermore, the present study also adds to the concepts that histopathological studies are one of the effective tools for eco-toxicology and risk assessments.

References

[1] L. Maltby, and C. Naylor, Preliminary observations on the ecological relevance of the Gammarus 'Scope for Growth' Assay: Effect of Zinc on Reproduction - Functional Ecology. New Horizons in Ecotoxicol, 4(3), 1990, 393-397.

[2] A.S. Prakasam, S. Ethupathy, and S. Lalitha, Plasma and RBCs antioxidant status in occupational male pesticide sprayers. Clin. Chim. Acta, 310, 2001, 107-112.

[3] P.J. John, Alteration of certain blood parameters of freshwater teleost Mystus vittatus after chronic exposure to Metasystox and Sevin. Fish Physiol and Biochem, 33, 2007, 15-20.

[4] D.S. Rathod, M.V. Lokhande, and V.S. Shembeka, Toxic impact of dimethoate on the biochemical composition of vital tissues of fish arias dussumieri . Shodh, Samiksha aur Mulyankan, 2(7), 2009

[5] P.K. Sibley, and N.K. Kaushik, Toxicity of microencapsulated permethrin to selected nontarget aquatic invertebrates. Archives of Environ. Contamination and Toxicology, 20, 1991, 168-176.

[6] O. Mohmed, Al-Jahdali, S. Ameen, Bin Bisher, and M. Islam Abu Zeid, Physiological and histological alterationas in rats liver induced by Sumithion®NP25/2.5EC, an insecticide used in dengue fever vector control in jeddah, Saudi Arabia. Saudi Journal of Biological Sciences, 14(1), 2007, 43-51.

[7] V.S. Leblond, and A. Hontela, Effects of in vitro exposures to cadmium, mercury, zinc, and 1-(2-chlorophenyl)-1-(4chlorophenyl)- 2, 2-dichloroethane on steroidogenesis by dispersed interrenal cells of rainbow trout (Oncorhynchus mykiss). Toxicol Applied Pharmacol, 157, 1999, 16-2.

[8] M. Lacroix, and A. Hontela, Regulation of acute cortisol synthesis by cAMP-dependent protein kinase and protein kinase C in a teleost species, the rainbow trout (Onychorhynchus mykiss). J. Endocrinology, 169, 2001, 71-78.

[9] J.M. Law, Issues Related to the Use of Fish Models in Toxicologic Pathology: Session Introduction. Toxicol Pathol, 31, $2003,49-52$.

[10] R. Shiekh, and J.S. Lee, Fish models in Impact assessment of carcinogenic potential of environmental chemical pollutants: an appraisal of Hermaphroditic Mangrove Killifish Kryptolebias marmoratus. Interdisciplinary studies on Environmental chemistrybiological responses to chemical pollutants. (Eds.) Y.Murakami, K., Nakayama, S., Kitamura, H., Iwata and S. tanabe, S. terrapub. 2008, 7-15.

[11] D. Bernet, H. Schmidt, W. Meier, P. Burkhardt-Holm, and T. Wahli, Histopathology in fish: Proposa for a protocol to assess aquatic pollution. J. Fish Disease, 22, 1999, 25-34. 
[12] L. Velkova-Jordanoska, and G. Kostoski, Histopathological analysis of liver in fresh (Barbus meridionalis petenyi Hekel) in reservoir Trebenista. Natura Croatica, 14, 2005, 147-153.

[13] M.M. Camargo, and C.B. Martinez, Histopathology of gills, kidney and liver of a Neotropical fish caged in an urban stream. Neotrop. Ichthyol, 5, 2007, 327-336.

[14] S. Akter, G.U. Ahmed, M.K. Roy, and N. Akter, Investigation of some small indigenous fish species from Ailee beel, Mymensingh. Progress. Agric, 17(1), 2006, 219-225.

[15] S.R. Pugzhuenda, N. Narendiran, R.G. Kumaran, S. Kumaran, and K.M. Alagappan, Effects of Malathion Toxicity in the Freshwater Fish Ophiocephalus punctatus -A Histotogical and Histochemical Study. World Journal of Fish and Marine Science, 1(3), 2009, 218224.

[16] P.H. Parikh, A. Rangrez, R. Adhikari-bagchi, and B.N. Desai, Effect of dimethoate on some histoarchitecture of fresh water fish oreocaromis mossambicus (Peters, 1852). The Bioscan, 5 (1), 2010, 55 - 58.

[17] H. Soufy, M. Soliman, E. El-Manakhly, and A. Gaafa, Some biochemical and pathological investigations on monosex Tilapia following chronic exposure to carbofuran pesticides. Global Veterinaria, 1, 2007, 45-52.

[18] E.L. Rodrigues, and E. Fanta, Liver histopathology of the fish Brachydanio Rerio Hamilton-Buchman after acute exposure to sublethal levels of the organophosphate Dimethoate 500. Revtabras. Zool, 15(2), 1998, 441-450.

[19] F.A.S. Mohamed, Histopathological Studies on Tilapia zillii and Solea vulgaris from Lake Qarun, Egypt. World Journal of Fish and Marine Sciences, 1(1), 2009, 29-39.

[20] F.A. Mohamed, Impacts of environmental pollution in the southern region of Lake Manzalah, Egypt, on the histological structures of the liver and intestine of Oreochromis niloticus and Tilapia zillii. J. Egypt. Acad. Soc. Environ. Develop, 2, $2001,25-42$.

[21] M. Ptashynski, R. Pedlar, R. Evan, C. Baron, and J. Klaver Kamp, Toxicology of dietary nickel in lake white fish (Coregonus clupeaformis). Aquat. Toxicol, 58, 2002, 229-247.

[22] E. Fanta, F. Rios, S. Romao, S. Vianna, and S. Freiberger, Histopathology of the fish Corydoras paleatus contaminated with sublethal levels of organophosphorus in water and food. Ecotoxicol. Environ. Safety, 54(2), 2003, 119-130.

[23] M. Atamanalp, T. Sisman, F. Geyikoglu, and A. Topal, The histopathological effects of copper sulphate on rainbow trout liver (Oncorhynchus mykiss). J. Fish. Aquat. Sci, 2008.

[24] S.A. Sakr, and S.M. Jamal Al lail, Fenvalerate Induced Histopathological and Histochemical Changes in the Liver of the Catfish Clarias Gariepinus. Journal of Applied Sciences Research, 1(3), 2005, 263-267.

[25] S. Teh, S.F. Hung, D. Teh, I. Deng, and Werner, Sublethal toxicity of orchard stormwater runoff in Sacramento splittail (Pogonichthys macrolepidotus) larvae. Mar. Environ. Res, 59(3), 2005, 203-216.

[26] F. Iqbal, I.Z. Qureshi, and M. Ali, Histopathological changes in the kidney of common carp, Cyprinus carpio, following nitrate exposure, J. Res. Sci, 15(4), 2004, 411-418.

[27] S.M. Thophon, E. Kruatrachuc, Upathau, P. Gills, S. Pokcthitiyook, Sahaphong and S. Jarikhuan, Histopathological alterations of white seabass, Lates calcarifer in acute and subchronic cadmium exposure. Environ. Pollution, 121, 2003, $307-320$.

[28] M. Yokote, Digestive system. In: An atlas of fish histology-normal and pathological features, in T. Hibiya (Ed.), Kodansha Ltd., Tokyo, 1982, 74-93.

[29] I. Kakuta, and S. Murachi, Physiological response of carp, Cyprinus carpio, exposed to raw sewage containing fish processing wastewater. Environ. Toxicol. Water Quality, 12, 1997, 1-9.

[30] M.E. Veiga, F. Rodrigues, Pacheco and M. Ranzani-Paiva, Histopathologic changes in the kidney tissue of Prochilodus lineatus, 1836 (Characiformes, Prochilodontidae) induced by sublethal concentration of Trichlorfon exposure. Brazilian Arch. Biol. Technol, 45(37), 2002, 171-175.

[31] B. Velmurugan, M. Selvanayagam, E. Cengiz and E. Unlu, The effects of fenvalerate on different tissues of freshwater fish Cirrhinus mrigala. J. Environ. Sci. Health (B), 42. 2007, 157-163.

[32] B.K. Das, and C. Mukherjee, A Histological study of carp (Labeo robita) exposed to hexachlorocyclohexane. Vet. Arhiv, 70(4), 2000, 169-180.

[33] S. Riaz, S.S. Alam, and A. Ikram, Histopathological changes observed in the heart and gizzard of quail chicks coturnix coturnix Japonica administrated by the different levels of chrome shaving. African Journal of Biotechnology, 5(19), 2006, 1765-1769. 